\title{
Analysis of Artificial Vision Techniques for Implementation of Virtual Instrumentation System to Measure Water Turbidity
}

\author{
Joseph James Guapacho, Javier Andrés Vargas Guativa and Javier Eduardo Martinez Baquero* \\ Faculty of Basic Sciences and Engineering, Universidad de los Llanos, Villavicencio, Colombia
}

Received 23 April 2020; Accepted 2 June 2021

\begin{abstract}
This paper presents the results of research framed in sustainable development goal number 6 called Clean water and Sanitation. Through research, it was found that water quality can be determined by measuring its turbidity, research objective was to design a measurement system which would allow to measure turbidity level in different samples using digital image analysis. This work was divided into different phases, starting with an image capture of the samples illuminated with LED light sources of different colors and different angles. Second instance, the processing and analysis of the captured images was carried out, and finally, with data obtained, mathematical model was obtained, it would allow the system to be designed. Study allowed observing the qualities and LED light depending behavior on its wave frequency and location from which the photographic shot is taken. Results obtained allowed finding a correlation between 0.95 and 1.0. Likewise, it was found that blue colored LED light with capture angle from the side offered the best correlation, therefore the most optimal option for the measurement was determined.
\end{abstract}

Keywords: Artificial vision, image processing, turbidity, virtual instrumentation, water quality

\section{Introduction}

Water is a fundamental element for existence of most living beings on planet Earth, human civilization throughout its history and development has been linked to use of water resources, with quality and abundance of this being the reason for growth, or collapse of entire peoples and empires.

However, despite importance of this resource for the life and well-being of living beings. Irresponsible human activities, exponential growth and concentration of human beings in large cities, cause that in many cases the quality of water consumed is very poor and even dangerous for living beings who need to take advantage of this resource.

This makes sea very important for scientists and engineers who implement techniques that require water quality, for protocols with this not only a better quality of life for humans, but also the conservation in good condition of the ecosystems. Examples of this is the work done by [1] in which a system was proposed that contributed to purification of water using electrofloculation, ozonation and ultraviolet radiation techniques, system allowed recovery of water contaminated by turbidity level, aerobic microorganisms, total coliforms and fecal coliforms or the article published by [2] which shows how a study was carried out in water purification plant, to determine how water turbidity influences water quality and how it can be correlated with other parameters of water and environment.

It's possible to know water quality through measurement of parameters. One of the fundamental parameters that allow determining water quality is turbidity. Turbidity is defined by the International Organization for Standardization (ISO) as the reduction of transparency of a liquid by the presence of undissolved particles of material other than the liquid itself.

*E-mail address: jmartinez@unillanos.edu.co ISSN: 1791-2377 @ 2021 School of Science, IHU. All rights reserved. doi:10.25103/jestr.144.20
First turbidimeters were developed in 1960s, since then there have been technological developments in these instruments that work using light sources and detectors, to determine dispersion of light and thus determine turbidity level. These turbidity measurement techniques are applied to life sciences, including bioprocesses, as shown by the work carried out by [3].

Measurement of parameters, whether industrial processes or monitoring systems, aims to control or make decisions regarding different quantities, such as pressure, flow, turbidity, temperature, etc. [4]. New measurement techniques and instruments are constantly being created and disclosed, as well as existing sensors are used to carry out necessary controls in different processes, such as instrumentation and control system for drinking water storage tanks implemented by [5] or virtual instrumentation system using an experimental resistance temperature detector, temperature sensor, developed within the Macrypt research group in Colombia by [6]. There are different methodologies and instruments that allow knowing quality of water through its parameters, in addition to turbidity, among the most relevant are: color, total solids, filterable solids (dissolved), dissolved oxygen, $\mathrm{pH}, \mathrm{CO}$, ammoniacal nitrogen, phosphates and toxins from sewage. The main of these variables and turbidity variable is reflected in different works such as the one presented by [7] which is a compilation that explained some of the methods that exist to determine characteristics in water or the work presented by proffesor [8] for the company "Empresa Municipal de Aguas de Córdoba S.A. - EMACSA" titled Physical, chemical and biological characteristics of the water.

Studies in which turbidimeter designs are made can be seen in the work done by [9]. That article shows how a device was developed which allowed to measure turbidity level and concentration of solids in water using the IR sensor that mobile phones have and which is usually used as proximity 
sensor. Another study that reflects design of a kit to measure turbidity was developed by [10]. This study refers to an instrument that allows to measure turbidity, in which neural network systems were implemented to calibrate and put it into operation.

Artificial vision or computer vision is defined as "the science that develops theoretical and algorithmic bases to obtain information about the real world from one or more images [11]. Within artificial vision, image processing refers to process by which an image is taken and a modified version of this image is produced, and image analysis that corresponds to the process by which a measurement, interpretation or decision is gotten.

There are works which artificial vision techniques have been used which include image processing and analysis to implement systems that allow to interpret turbidity level in water, whether for large bodies of water, by means of use of satellite images or images taken by aircraft, examples of which are: The work entitled Monitoring of Water Parameters of the Aracena Reservoir Using Landsat Images published by [12]; Study published by [13] titled Generation of Indicators for Monitoring Quality of Coastal Waters. Evolution of Turbidity at the Mouth of the Guadalquivir River; or paper Turbidity Mapping using Digital Camera Images Captured by a Digital Camera From Low Altitude Airborne Platform which shows the process to propose a mathematical model that allows to measure the turbidity of water from images taken at low altitude by means of a digital camera that was placed on a light aircraft. In small containers, artificial vision techniques and digital cameras are also used to determine water turbidity level in the Sample of it can be found in the works published by [14].

Objective of this work is to implement a system to measure turbidity in $625 \mathrm{ml}$ water samples that had an approximate turbidity of between 4.61 and 982 Nephelometric Turbidity Unit (NTU). Using a 5mm LED light as a light source and a camera photographic as a detector; to determine level of dispersion through image processing and analysis, for which images of water samples that had different urbidity levels were used, which were captured with the camera, samples were illuminated with LED light sources of different wavelength (White, Green, Blue, Red, Yellow), to determine which offered the possibility of generating a system that made use of image analysis and LED lighting, in order to create a non-immersive method that allowed determining water turbidity level in samples and storage places of this type of liquid.

\section{Methodology}

To formulate a mathematical model reliable capable to determine turbidity level and percentage of sediments present in water samples. It was decided to carry out an experimental research methodology, characterized by intentional manipulation of one or more independent variables, to observe / measure their influence on one or more dependent variables [15].

A webcam with the following features was used to carry out the experiment, $1080 \mathrm{p}$ video at 30 frames per second (up to $1920 \times 1080$ pixels), H.264 video compression, built-in stereo microphones with noise reduction, built-in automatic privacy cover, Autofocus, auto low-light correction, USB 2.0 highspeed certification (USB 3.0 compatible), tripod-compatible universal clip.
Research carried out seeks to test the hypothesis of the possibility of making a measurement of turbidity level in water and / or percentage of sediments, using an artificial vision system. For this LED lighting was used and light beams behavior in water was interpreted. In experimentation process, changes will be made to independent variables: LED lighting color (Red, Yellow, Blue, White and Green); Illumination level ((45-55 lumens), (150-170 lumens); Camera position (Side and Top); Sediment percentage and Turbidity level (Used in 11 different samples between $0 \mathrm{~g}(\%$ sediment) - 4, 61 NTU and $2 \mathrm{~g}$ - 982 NTU); and Time (0 - 60 Seconds, since water and sediment solution is shaken). Dependent variables that were taken into account for study were total histogram value (Sum gray level * number of pixels in each level) and Higher histogram value (detection of gray level with higher pixel level).

For development of methodology, a process was divided into three phases; Phase 1. Photographic record, Phase 2. Image treatment and analysis, Phase 3. Data analysis (Descriptive Statistics; Correlational Statistics; and Inferential Statistics). Which are explained as follow.

Phase 1. Photographic record. Light-tight drawer was used, which allowed to locate a container inside that contained: Water and sediment solution; and different light sources. Drawer offered possibility of locating the digital photographic camera in the top and / or lateral part, offering different capture angles. Photographic records were made for 11 different samples of water and sediments and were repeated between 2-3 times to eliminate error margin, in addition they were also taken at 0 and 60 seconds, in order to determine changes in turbidity that Samples suffered over time. So a total of 560 photographic shots were processed and analyzed.

Phase 2. Image processing and analysis. Some images required processing, which consisted of removing background from image, leaving only space in the image that contained the container with sample and in a conversion of the image from RGB to grayscale (pixels passed from being represented by 3 different values (Red, Green and Blue) to having a single value that corresponded to a value on a gray scale made up of 256 levels, ranging from black (0) to white (255)). After image processing, an image analysis was implemented using image histogram, obtaining from it dependent variables Total histogram value and highest histogram value.

Phase 3. Data analysis. Data analysis sought to know and explain reality to control and make predictions, was supported by use of different types of statistics (Descriptive Statistics; Correlational Statistics; and Inferential Statistics). They are explained in more detail below.

Descriptive statistics. Independent and dependent variables are related by means of tables and graphs, thus allowing an observation and description of the behavior in variables studied.

Correlational statistics. Information is extracted from tables and graphs, to formulate mathematical models that show existed correlation between independent and dependent variables.

Inferential Statistics. Mathematical models obtained after performing a correlation allow a detailed study to be carried out, which provides the possibility to making analyzes and predictions about future observations.

\section{Results and Discussion}

\subsection{Information capture}


Joseph James Guapacho, Javier Andrés Vargas Guativa and Javier Eduardo Martinez Baquero/

Journal of Engineering Science and Technology Review 14 (4) (2021) 161 - 168

Database is created with 560 photographic shots, in these a decrease in the LED light in the sample is evidenced as percentage of sediments increases and with it the turbidity level. In table 1, 2 and 3 it is reflected what happens as turbidity increases.

\subsection{Image processing and analysis}

3.2.1 Image processing

Image processing involved a transformation of them, segmenting the samples, keeping only one color band (RGB) or converting scales to gray. Figure 1 shows processing that is performed to the photograph of a sample illuminated blue light and with a turbidity value of 185 Nephelometric Turbidity Unit (NTU).

Table 1. Photo Shows LED light shots from the side.

\begin{tabular}{|c|c|c|c|c|c|}
\hline Color & Yellow & White & Blue & Red & Green \\
\hline $\begin{array}{l}625 \mathrm{ml}- \\
0.5 \mathrm{~g} \\
185 \mathrm{NTU}\end{array}$ & & & & & \\
\hline $\begin{array}{l}625 \mathrm{ml}- \\
1.5 \mathrm{~g} \\
775 \mathrm{NTU}\end{array}$ & & & & & \\
\hline
\end{tabular}

Table 2. Photographs indirect LED light (White) taken from the side, with background removal.

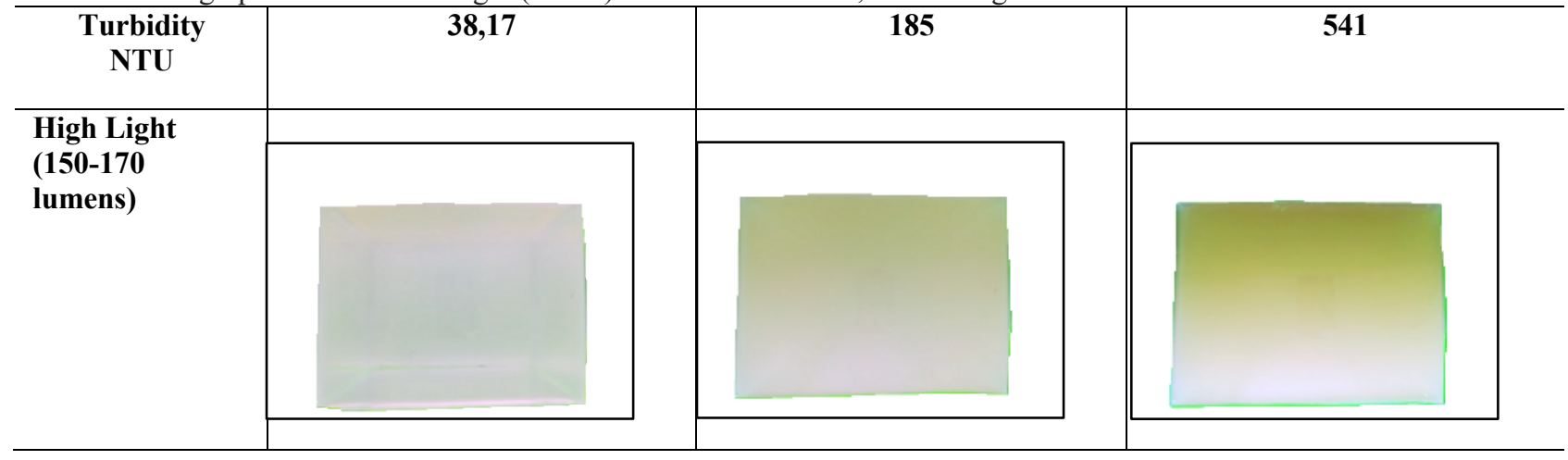

Table 3. Photographs LED light shots from the top.

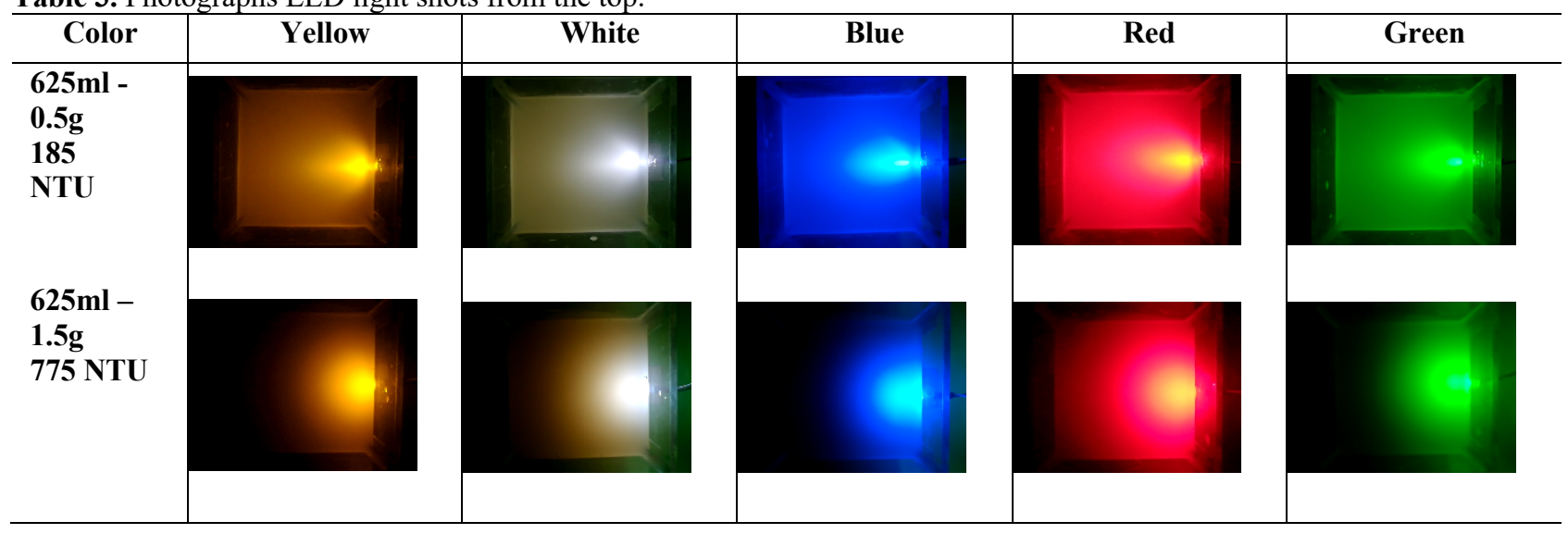
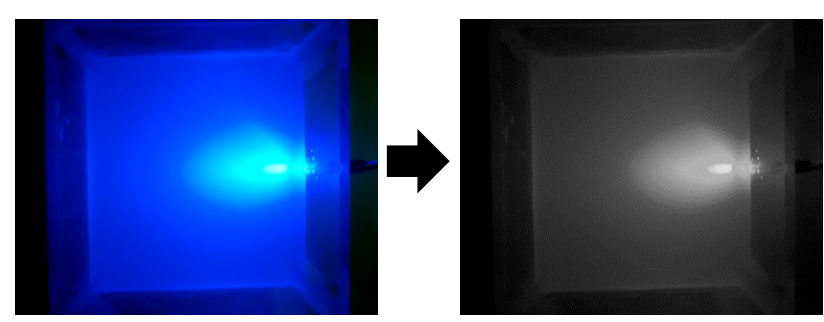

Fig. 1 Image processing.

\subsubsection{Image Analysis}

Once the image processing was made, which allowed making modifications to images required, they were analyzed, using histogram for this task. Histogram data allows to determine 
different shades of gray present in image and number of pixels present in this shade.

Figure 2 shows histogram obtained as result of figure 1, this histogram has a value of 13551876 , this value is obtained by multiplying level of gray tone by the number of pixels that have that tone and to add all these values.

Table 4 represents the relationship between amount of sediment, turbidity value and total histogram value of the figure 2 .

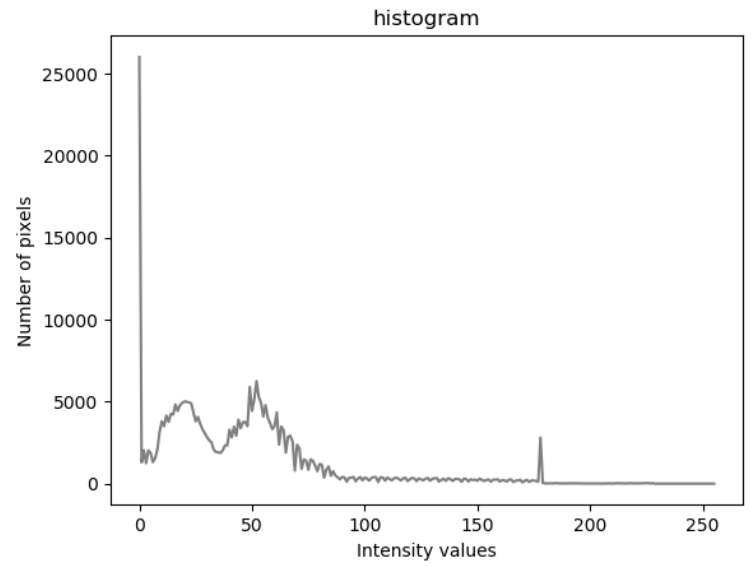

Fig. 2 Histogram.

\subsection{Statistic analysis}

Table 4. Relationship histogram value.

\begin{tabular}{c|c|c}
\hline Sediments in $\mathbf{6 2 5} \mathbf{~ m l}$ of Water-Grams & Turbidity Value- NTU & Total value Histogram \\
\hline 0,5 & 185 & 13551876 \\
\hline
\end{tabular}

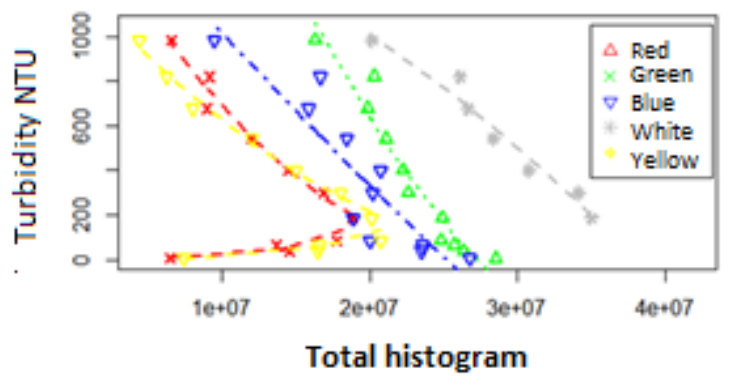

Fig. 3 Gray scale-Lateral.

Figure 7 and figure 8 show relationship between turbidity level and histogram value samples photographs when they are

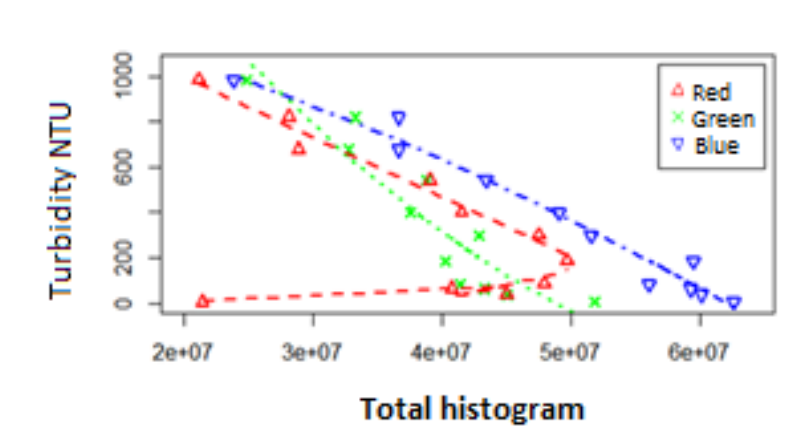

Fig. 5 RGB Bands-Lateral.

\subsubsection{Descriptive statistics}

Analysis of the images gave value of the histogram, two and three shots were taken for each sample, at a time of 0 and 60 seconds, these values were averaged allowing graphs to be obtained for different capture angles and processing methods. Graphs obtained show mathematical models polynomial equations of second degree are able to describe relationship between the turbidity level of sample and histogram of the image.

Figures 3 and 4 show relationship between turbidity level and histogram value of the samples photographs when they are subjected to LED lighting (Red; Green; Blue; White; or Yellow) from the top and lateral, the samples being processed by a gray scale transformation. It was observed that mathematical models described the distribution of samples well, although with red and yellow led light, it is observed that it has an erratic behavior, which made them discard as an option, to make predictions.

Figure 5 and figure 6 show relationship between turbidity level and histogram value of the photographs of the samples when they are subjected to LED lighting (Red; Green; Blue) from the top and side, samples being processed by extracting only one band for analysis (Red, Green, Blue). It was observed that mathematical models adequately described distribution of samples, although erratic behavior was observed with red LED light, which made it discard as a viable option, to make future predictions.

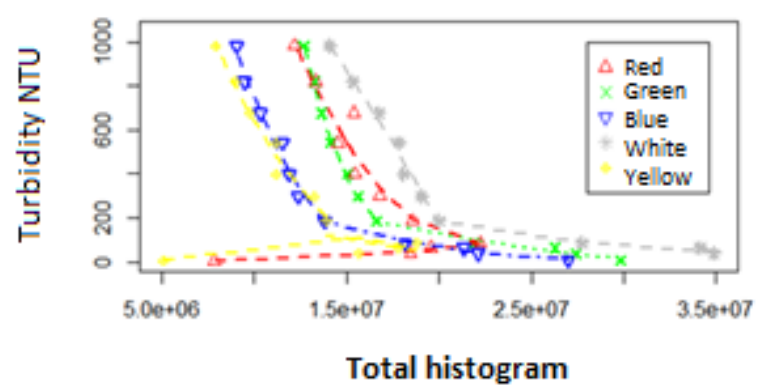

Fig. 4 Gray scale-Top.

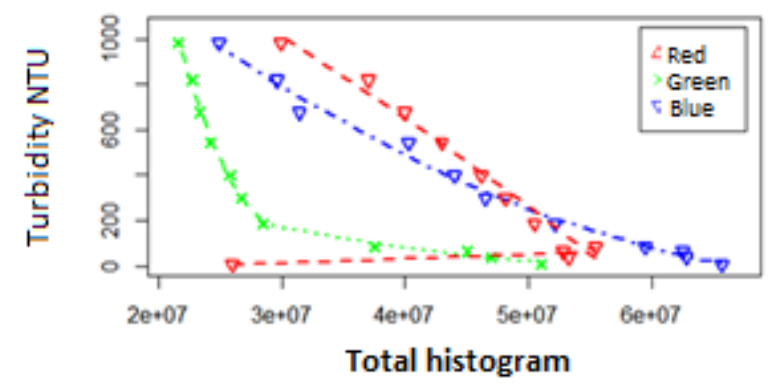

Fig. 6 RGB Bands-Top.

subjected to white LED lighting with different levels (50 and 150 lumen) from lateral part, samples processed by 
segmentation of the container with the sample and transformation to gray scale. It was observed that mathematical models adequately described the distribution of

\section{Light level change - Highest value}

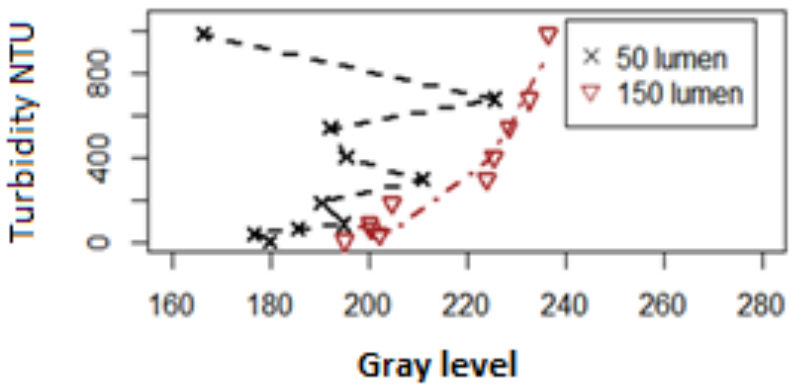

Fig. 7 RGB Bandas - Top.

\subsubsection{Correlational statistics}

Correlation between turbidity level and image histogram, as stated, is reflected by different mathematical models of polynomial equations of the second degree. In some cases, due to the distribution of data, segmentation was chosen, thus samples for 150 lumens, but samples with 50 lumens showed erratic behavior, which made it to be ruled out as a viable option to make future predictions.

\section{Light level change - Total value}

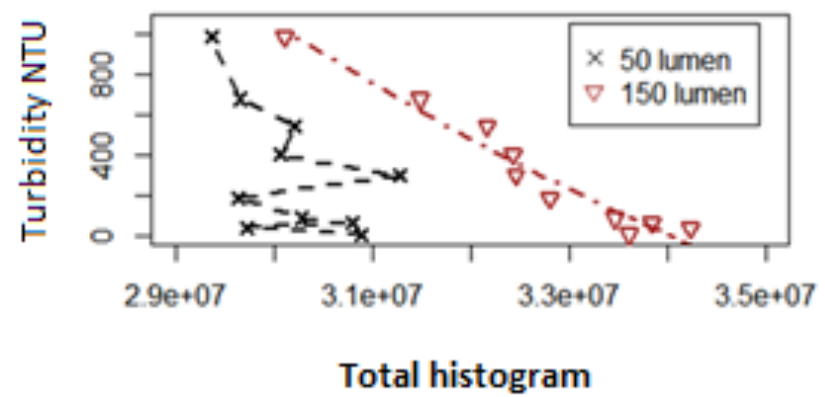

Fig. 8 RGB Bandas - Top.

allowing a correlation to be obtained. Tables 5, 5, 6, 7, 8 show mathematical models and level of correlation between them and those measured are shown. The correlation values obtained were greater than 0.80 or $80 \%$, even reaching 0.9946 or $99.5 \%$.

Table 5. Gray scale - lateral.

\begin{tabular}{c|c|c} 
Table 5. Gray scale - lateral. & \multicolumn{1}{c}{ Polynomial Equation } & Correlation Polynomial Equation \\
Color & $2.841 \mathrm{e}-13 \mathrm{x}^{\wedge} 2-7.676 \mathrm{e}-05 \mathrm{x}+1.754 \mathrm{e}+03$ & 0.8014 \\
Blue(4,61-982) & $1.539 \mathrm{e}-12 \mathrm{x}^{\wedge} 2-2.696 \mathrm{e}-05 \mathrm{x}+1.172 \mathrm{e}+02$ & 0.8275 \\
Red(4,61-185 & $2.335 \mathrm{e}-13 \mathrm{x}^{\wedge} 2-6.059 \mathrm{e}-07 \mathrm{x}-3.755 \mathrm{e}+00$ & 0.9209 \\
Yellow(4,61-84) & $2.478 \mathrm{e}-12 \mathrm{x}^{\wedge} 2-2.051 \mathrm{e}-04 \mathrm{x}+3.750 \mathrm{e}+03$ & 0.932 \\
Green(4,61-982) & $-7.059 \mathrm{e}-13 \mathrm{x}^{\wedge} 2-1.534 \mathrm{e}-05 \mathrm{x}+1.597 \mathrm{e}+03$ & 0.9603 \\
White $(185-982)$ & $2.261 \mathrm{e}-12 \mathrm{x}^{\wedge} 2-1.200 \mathrm{e}-04 \mathrm{x}+1.660 \mathrm{e}+03$ & 0.9743 \\
Red(185-982) & $5.383 \mathrm{e}-13 \mathrm{x}^{\wedge} 2-6.245 \mathrm{e}-05 \mathrm{x}+1.204 \mathrm{e}+03$ & 0.9828 \\
Yellow $(84-982)$ &
\end{tabular}

Table 6. Gray scale - Top.

\begin{tabular}{c|c|c}
\hline Color & Polynomial Equation & Correlation Polynomial Equation \\
\hline Yellow(4,61-185) & $8.127 \mathrm{e}-13 \mathrm{x}^{\wedge} 2-1.375 \mathrm{e}-05 \mathrm{x}+5.342 \mathrm{e}+01$ & 0.9954 \\
Red(84,2-982) & $4.662 \mathrm{e}+03 \mathrm{x}^{\wedge} 2-4.166 \mathrm{e}-04 \mathrm{x}+9.468 \mathrm{e}-12$ & 0.9291 \\
Green(4,61-185) & $3.577 \mathrm{e}-13 \mathrm{x}^{\wedge} 2-2.932 \mathrm{e}-05 \mathrm{x}+5.695 \mathrm{e}+02$ & 0.9674 \\
Red(4,61-84,2) & $5.126 \mathrm{e}-13 \mathrm{x}^{\wedge} 2-9.749 \mathrm{e}-06 \mathrm{x}+4.935 \mathrm{e}+01$ & 0.9726 \\
Yellow(185-982) & $9.592 \mathrm{e}-12 \mathrm{x}^{\wedge} 2-3.391 \mathrm{e}-04 \mathrm{x}+3.068 \mathrm{e}+03$ & 0.982 \\
White(38,1-185) & $4.992 \mathrm{e}-13 \mathrm{x}^{\wedge} 2-3.658 \mathrm{e}-05 \mathrm{x}+7.170 \mathrm{e}+02$ & 0.9796 \\
Blue(185-982) & $1.373 \mathrm{e}-11 \mathrm{x}^{\wedge} 2-4.768 \mathrm{e}-04 \mathrm{x}+4.141 \mathrm{e}+03$ & 0.9797 \\
Blue(4,61-185) & $7.540 \mathrm{e}-13 \mathrm{x}^{\wedge} 2-4.413 \mathrm{e}-05 \mathrm{x}+6.482 \mathrm{e}+02$ & 0.9843 \\
White(185-982) & $-3.723 \mathrm{e}-12 \mathrm{x}^{\wedge} 2-1.059 \mathrm{e}-05 \mathrm{x}+1.869 \mathrm{e}+03$ & 0.9857 \\
Green(185-982) & $3.457 \mathrm{e}-11 \mathrm{x}^{\wedge} 2-1.213 \mathrm{e}-03 \mathrm{x}+1.081 \mathrm{e}+04$ & 0.9936 \\
\hline
\end{tabular}

Table 7. RGB Bands - Top.

\begin{tabular}{c|c|c}
\hline Color & Polynomial Equation & Correlation Polynomial Equation \\
\hline $\operatorname{Red}(4,61-84,2)$ & $3.713 \mathrm{e}-13 \mathrm{x}^{\wedge} 2+-2.761 \mathrm{e}-05 \mathrm{x}+4.717 \mathrm{e}+02$ & 0.8755 \\
Green(4,61-185) & $1.210 \mathrm{e}-13 \mathrm{x}^{\wedge} 2-1.707 \mathrm{e}-05 \mathrm{x}+5.694 \mathrm{e}+02$ & 0.9675 \\
$\operatorname{Red}(84,2-982)$ & $-1.302 \mathrm{e}-13 \mathrm{x}^{\wedge} 2-2.739 \mathrm{e}-05 \mathrm{x}+1.954 \mathrm{e}+03$ & 0.9827
\end{tabular}


Table 8. RGB Bands - lateral.

\begin{tabular}{c|c|c}
\hline Color & Polynomial Equation & Correlation Polynomial Equation \\
\hline Red(4,61-185 & $4.255 \mathrm{e}-13 \mathrm{x}^{\wedge} 2-2.531 \mathrm{e}-05 \mathrm{x}+4.255 \mathrm{e}-13$ & 0.722 \\
Green(4,61-982) & $5.943 \mathrm{e}-13 \mathrm{x}^{\wedge} 2-8.884 \mathrm{e}-05 \mathrm{x}+2.916 \mathrm{e}+03$ & 0.8569 \\
Blue(4,61-982) & $-1.518 \mathrm{e}-13 \mathrm{x}^{\wedge} 2-1.329 \mathrm{e}-05 \mathrm{x}+1.408 \mathrm{e}+03$ & 0.9689 \\
$\operatorname{Red}(185-982)$ & $2.140 \mathrm{e}-14 \mathrm{x}^{\wedge} 2-2.793 \mathrm{e}-05 \mathrm{x}+1.548 \mathrm{e}+03$ & 0.9727 \\
\hline
\end{tabular}

Table 9. Light level change LED (white) indirect - lateral.

\begin{tabular}{c|c|c}
\hline Color & $\begin{array}{c}\text { Polynomial Equation } \\
(\mathbf{1 5 0 - 1 7 0 )} \text { lumen }\end{array}$ & Correlation Polynomial Equation \\
\hline Histo. Complete & $-8.753 \mathrm{e}-13 \mathrm{x}^{\wedge} 2-2.428 \mathrm{e}-04 \mathrm{x}+9.055 \mathrm{e}+03$ & 0.9548 \\
Histo. Highest value & $0.7582 \mathrm{x}^{\wedge} 2-307.8494 \mathrm{x}+31297.5642$ & 0.9522 \\
\hline
\end{tabular}

\section{Validation}

For validation, software is implemented in python and PYQT language, which allows capturing images, processing and analyzing them, to deliver calculated turbidity value and histogram value to the operator. See figures 9 and 10 .

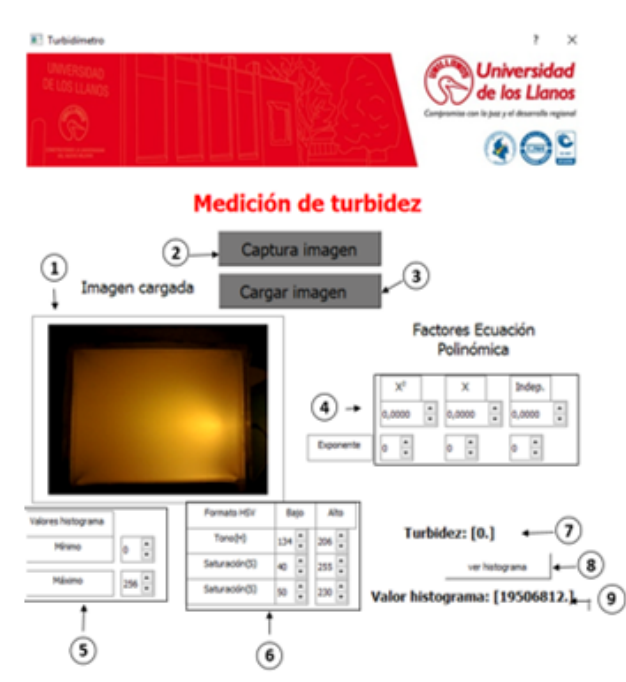

Fig 9. Software turbidity Gray scale.Software developed by the authors.

Efficiency of the models proposed was carried out, eq. (1) was chosen. This is generated when analyzing RGB bands using photographs of the samples with Blue LED lighting taken from the top.

$$
E f=3.245 \mathrm{e}-13 \mathrm{x}^{\wedge} 2-5.291 \mathrm{e}-05+2.084 \mathrm{e}+03
$$

This is due to having only one mathematical model that described relationship between turbidity level and histogram, with correlation level of 0.9212 or $0.99 \%$. Validation is done taking level of error, which presented less than $10 \%$ for $80 \%$ levels of the samples, as shown in table 10.

Finally and synthesizing, various techniques combination was proposed, such as those used for design of instruments
1. $\rightarrow$ Image-loaded. It's the -image-loaded into the-software-onwhich analysis is performed to determine turbidity value ofthe sample.

2. $\rightarrow$ Button, Capture -image. This - button - allows - capturing an image through camera, while-showing-sector that will-beselected from the-image.

3. $\rightarrow$ Button, Upload image. This button allows selecting search and - selecting an -image - found on the computer-where the program is running. $\Phi$

4. $\rightarrow$ Factors PolynomialEquation. In this section you must entermathematicalmodel-values $\square$ generated. $\uparrow$

5. $\rightarrow$ Selection of histogram values. It-allows selecting the range of - values-回 回 of the histogram on which the analysis-will be performed. $\uparrow$

6. $\rightarrow$ Maximum values - 回 Selection $\cdot$ of $\cdot H \cdot$ and $-S \cdot$ in $\cdot$ the $\cdot H S V \cdot$ color format. This selection-allows to help in selecting the sectorof-image - to - be-analyzed- when-image-capture-process isbeing carried out.

7. $\rightarrow$ Turbidity. Turbidity Value delivered for virtual instrumentsystem.

8. $\rightarrow$ Button, see histogram. This buttonallows to see histogram graph of the loaded image. through a detector which measures dispersion that occurs from a light source due to contamination of sediments in water and that is. They are reflected in the publications: "Construction with Open Technologies of a Low Cost Turbidity Sensor" (Román Herrera, Loza, Segura, \& Dabirian, 2016); "Multibeam optical system and neural processing for turbidity measurement"(Postolache et al., 2007); or "Estimation of turbidity and total suspended solid concentration in environmental water bodies using a smartphone" (Hussain \& Nath, 2015). Characterization that is carried out using satellite images and digital cameras that allow determining turbidity level using histogram of images that are captured, processed and analyzed, to measure turbidity in large bodies of water or small samples. 


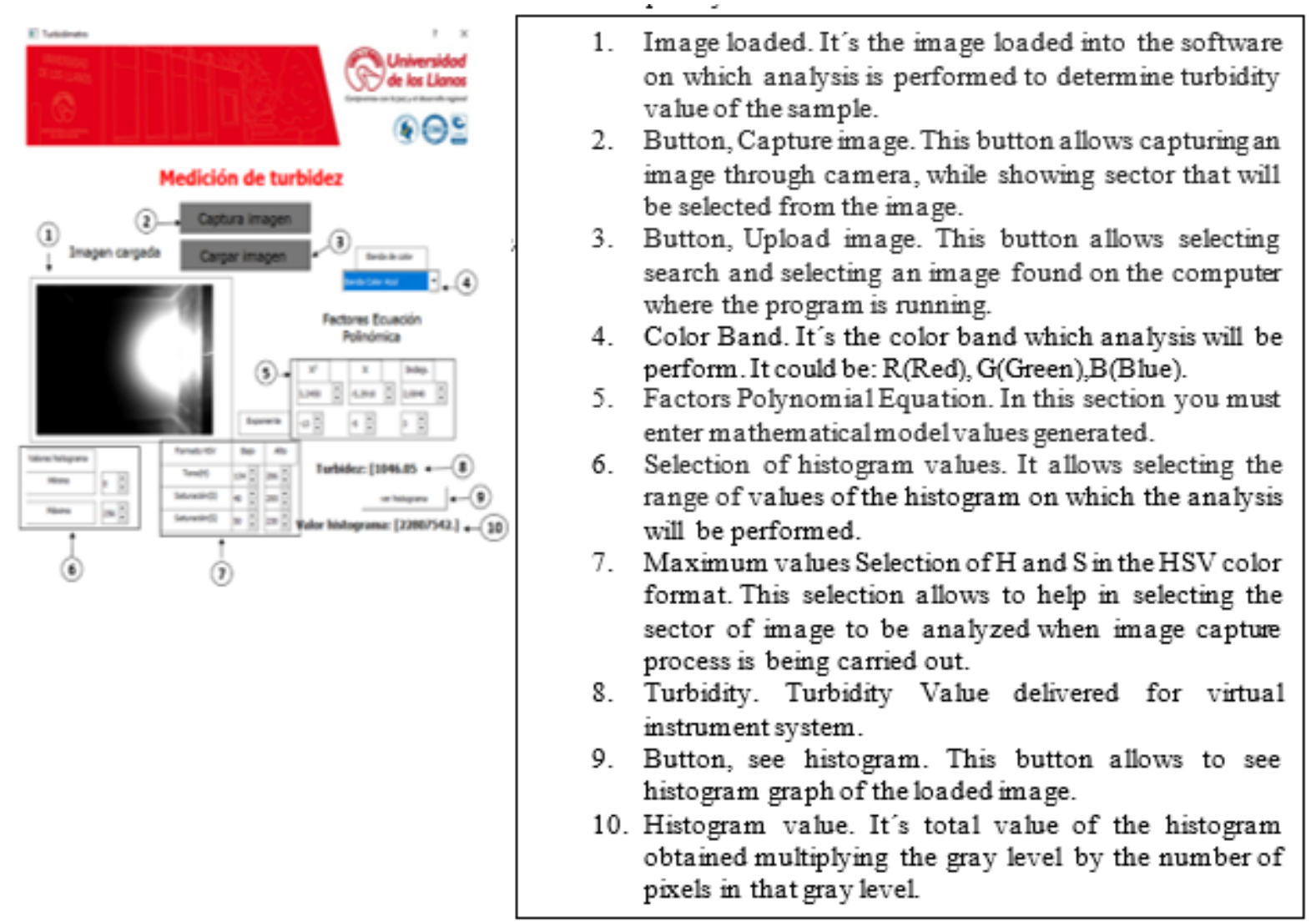

Fig 10. Software turbidity Band RGB. Software developed by the authors.

Table 10. Mathematical validation model.

\begin{tabular}{c|c|c|c|c}
\hline $\begin{array}{c}\text { Sediments in 625 ml of Water- } \\
\text { Grams }\end{array}$ & Turbidity Value- NTU & $\begin{array}{c}\text { Total value } \\
\text { Histogram }\end{array}$ & $\begin{array}{c}\text { Total value Calculated- } \\
\text { NTU }\end{array}$ & \% Error \\
\hline 0,0 & 4,6 & 65676424 & 8,8 & 89,9 \\
0,1 & 38,2 & 63347800 & 34,5 & 9,7 \\
0,1 & 62,2 & 62310480 & 47,1 & 24,3 \\
0,2 & 84,2 & 59791870 & 80,5 & 4,4 \\
0,5 & 185,8 & 52257910 & 205,2 & 10,0 \\
0,8 & 297,8 & 47651816 & 299,6 & 0,6 \\
1,0 & 399,1 & 42490016 & 421,7 & 5,7 \\
1,2 & 541,0 & 38926850 & 516,1 & 4,6 \\
1,5 & 676,7 & 33140276 & 686,9 & 1,5 \\
1,8 & 819,5 & 27671456 & 868,4 & 6,0 \\
2,0 & 982,7 & 24271568 & 991,0 & 0,8 \\
\hline
\end{tabular}

In proposed method, correlation between turbidity and histogram of images was carried out, as planned in the work "Application of the Multidirection-Multiresolution Image Fusion Methodology (MDMR) to the Estimation of Turbidity in Lagos" (Lillo-Saavedra \& Gonzalo, 2008); "Turbidity Mapping using Digital Camera Images Captured by a Digital Camera From Low Altitude Airborne Platform"(Lim, Matjafri, \& Abdullah, 2009); "Turbidity detection using Image Processing" (Karnawat \& Patil, 2016); and others.

It allowed verifying that it is possible to formulate a system for turbidity measurement using artificial vision and use of a light source, facilitates and makes measurement technique more accurate.

This development allowed to implement artificial vision systems to determine turbidity levels either in small samples or large industrial systems that require real-time monitoring in which it is not necessary to have samples to take to the laboratory, but rather to do it directly in the laboratory. workplace.

Based on error theory, relative truncation errors were determined. These errors are generated by the use of the approximation model through curve fitting. In this way knowing the deviation of the measured value error against the real value was found the relative truncation error equivalent to $5 \%$. Likewise, regarding the repeatability of the measurements, it was possible to calculate the accuracy based on the behavior of the modal frequency. In this way, the relative modal frequency with respect to the accumulated relative frequency had a variation of $5 \%$. Therefore, it was determined that the precision is $95 \%$.

\section{Conclusions}


Project developed allows determining it is possible to implement a system that makes use of artificial vision techniques and LED lighting, to determine with an acceptable error rate level of turbidity in water sample.

It was determined that light emitted by Blue color LED, for superior method (gray scale), Top (RGB color bands), Lateral (RGB color bands) is the most viable color, since behavior curve that it is generated by making histogram of this color with turbidity level, they had a balanced variation from 4.61 NTU to 982 NTU, with the possibility of generating mathematical models with correlation level between 0.95 and 1.0 .

Mathematical models generated when direct lighting was performed with an LED light, presented higher correlation (up to 0.99 ) for polynomial models of degree two, compared to correlation obtained when light level is constant in the container (maximum 0.95).
Numerical simulation carried out and compared with respect to behavior of the system was efficient with an accuracy and average accuracy of $95 \%$.

\section{Acknowledgements}

The authors are grateful to University of the Llanos, who through the last years has significantly influenced our lives allowing us to grow as people and professionals through the development of research projects performed in the School of Engineering with the Research Group (EYSI, MACRYPT).

This is an Open Access article distributed under the terms of the Creative Commons Attribution License.

\section{References}

1. Vargas, J. A. (2018). Desarrollo de un sistema electrónico que aporta a la potabilización de agua mediante electrofloculación, ozonificación y radiación ultravioleta. Espacios, 39(39). Retrieved from

https://www.researchgate.net/publication/327988131_Desarrollo_d e un sistema electronico que aporta a la potabilizacion de agu a_mediante_electrofloculacion_ozonificacion_y_radiacion_ultravio leta.

2. Marcó, L., Azario, R., Metzier, C., \& García, M. del C. (2004). Ingeniería sanitaria y ambiental publicación de la Asociación Argentina de Ingenería Sanitaria y Ciencias del Ambiente AIDIS Argentina. Ingeniería sanitaria y ambiental. [s.n.]. Retrieved from http://bases.bireme.br/cgi-

bin/wxislind.exe/iah/online/?IsisScript=iah/iah.xis\&src=google\&ba $\mathrm{se}=$ REPIDISCA\&lang $=$ p\&nextAction $=\operatorname{lnk} \& \operatorname{exprSearch}=23832 \&$ in dexSearch $=$ ID

3. Acebedo Gonzáles, D., \& Hernández García, A. T. (2013). Los métodos Turbidimétricos y sus aplicaciones en las ciencias de la vida. Revista CENIC. Ciencias Biológicas (Vol. 44). Centro Nacional de Investigaciones Científicas. Retrieved from http://www.redalyc.org/html/1812/181226886003/

4. Creus, A. (2011). Instrumentación Industrial (8th ed.). Barcelona, España: Alfaomega.

5. Vargas Guativa, J. A., López Velásquez, J. A., \& Conde Cárdenas, L. (2015). Sistema de Instrumentación y Control para Tanques de Almacenamiento de Agua Potable. INGENIARE, 9(17), 69. https://doi.org/10.18041/1909-2458/ingeniare.17.563

6. Vargas Guativa, J. A., Almanza León, C. J., \& Guapacho Castro, J. J. (2016). Sistema de instrumentación virtual utilizando un sensor Nephelometric Turbidity Unit experimental. Ingenium Revista de La Facultad de Ingeniería, 17(34), 31-46. https://doi.org/10.21500/01247492.2737

7. Martínez, A. D. (2006). Métodos de análisis físicos y espectrofométricos para el análisis de aguas residuales. Technología En Marcha, 19(2), 31-40.

8. Marín Galvín, R. (n.d.). Características físicas, químicas y biológicas de las aguas. $\quad$ Retrieved from http://api.eoi.es/api_v1_dev.php/fedora/asset/eoi:48101/component e48099.pdf

9. Hussain, I., \& Nath, P. (2015). Estimation of turbidity and total suspended solid concentration in environmental water bodies using a smartphone. International Conference on Electronic Devices, Circuits, Applied Electronics and Communication Technology (EDCAECT 2015). https://doi.org/10.13140/RG.2.1.4194.0243

10. Postolache, O. A., Girão, P. M. B. S., Pereira, J. M. D., \& Ramos, H. M. G. (2007). Multibeam optical system and neural processing for turbidity measurement. IEEE Sensors Journal, 7(5), 677-684. https://doi.org/10.1109/JSEN.2007.894896

11. Haralick, R. M., \& Shapiro, L. G. (1992). Computer and robot vision. Addison-Wesley Pub. Co. Retrieved from https://dl.acm.org/citation.cfm?id=573190

12. Polvorios, A. J., \& Hernández, M. J. (2001). Monitorización de Parámetros Hídricos del Embalse de Aracena Mediante Imágenes Landsat. Teledetección, Medio Ambiente y Cambio Global, 334-337.

13. Moreira, J. M., Carpintero, I. R., Crespo, R., Granado, L., Montoya, G., Pino, I., \& Rodríguez, A. (2009). Generación De Indicadores Para El Seguimiento De La Calidad De Las Aguas Litorales. Evolución De La Turbidez En La Desembocadura Del Río Guadalquivir. In S. Montesinos Aranda \& L. Fernández Fornos (Eds.), Teledetección: Agua y desarrollo sostenible. XIII Congreso de la Asociacion Española de Teledetección (pp. 197-200). Calatayud. $\quad$ Retrieved $\quad$ from http://www.aet.org.es/congresos/xiii/cal50.pdf

14. Karnawat, V., \& Patil, S. L. (2016). Turbidity detection using Image Processing. In International Conference on Computing, Communication and Automation (ICCCA 2016)ication and Automation (ICCCA 2016) (pp. 1086-1089). IEEE. https://doi.org/10.1109/CCAA.2016.7813877

15. Rodríguez Gómez, D., \& Valldeoriola Roquet, J. (2009). Metodología de la investigación. Barcelona. Retrieved from http://myuvmcollege.com/uploads/lectura2011-09/Metodología de investigación-2064.pdf 